\title{
ASPECTOS LEGAIS E PERCEPÇÕES SOBRE AS ESTRATÉGIAS PARA CIDADES INTELIGENTES E CRIATIVAS: ESTUDO DA CIDADE DE CHAPECÓ (SC)
}

Andrezza Aparecida Saraiva Piekas ${ }^{1}$

Rógis Juarez Bernardy ${ }^{1}$

Simone Sehnem ${ }^{1}$

Juliana Fabris ${ }^{2}$

${ }^{1}$ Universidade do Oeste de Santa Catarina (UNOESC)

${ }^{2}$ Universidade Comunitária da Região de Chapecó 


\section{ASPECTOS LEGAIS E PERCEPÇÕES SOBRE AS ESTRATÉGIAS PARA CIDADES INTELIGENTES E CRIATIVAS: ESTUDO DA CIDADE DE CHAPECÓ (SC)}

\section{Resumo}

As cidades brasileiras tiveram um impulso no desenvolvimento econômico a partir da intensificação do processo de globalização que contribuiu para a pulverização de atividades econômicas, para além dos grandes centros urbanos. Neste contexto está Chapecó (SC), cidade polo regional que possui uma rede urbana centrada em pequenos municípios. Na perspectiva da dinamização das atividades econômicas, a pesquisa teve como objetivo verificar os aspectos legais e o ponto de vista de lideranças sobre a perspectiva da formação de uma cidade inteligente e criativa, com base nos pressupostos de Caragliu et al. (2011). As contribuições da pesquisa estão associadas à análise do processo de formação de Chapecó (SC) como cidade inteligente e criativa. $\mathrm{O}$ estudo de caso qualitativo contemplou a análise de documentos legais municipais aliada à análise de conteúdo das entrevistas com lideranças comunitárias e de entidades locais. Como resultado, observou-se que a transição para uma cidade inteligente e criativa é embrionária, com demandas estruturais, culturais, sociais, econômicas, institucionais e ambientais a serem atendidas.

Palavras-chave: Cidades Inteligentes, Cidades Criativas, Desenvolvimento.

\section{Introdução}

Em 2017 a cidade de Chapecó (SC) completou cem anos, com aproximadamente 213 mil habitantes (IBGE, 2017). Ao longo dos anos, o crescimento local foi construído pelos pioneiros, empreendedores e pessoas que acreditaram no potencial da cidade. Tradicionalmente, Chapecó é reconhecida como a Capital do Oeste, pela capacidade de centralizar e integrar, em âmbito regional, os municípios do Grande Oeste Catarinense. A cidade sedia eventos de negócios nacionais e internacionais, o aeroporto regional, incorpora atividades de inúmeros setores, tais como, indústria, comércio, agronegócio, prestação de serviços, saúde, educação, entre outros.

Por outro lado, há desafios a serem superados, a fim de fomentar o desenvolvimento de uma cidade inteligente e criativa. Entre os principais, estão as assimetrias observadas em diferentes bairros e que acentuam as assimetrias urbanas, especialmente na empregabilidade, na geração de renda, no acesso a serviços de qualidade e na infraestrutura pública básica. Isso demanda investimentos em projetos e iniciativas de atuação em rede, que orientem a cidade para negócios; em encaminhamento no quesito inclusão social; no fomento às indústrias criativas; no fortalecimento do papel do capital social e relacional; e, na priorização da sustentabilidade social e ambiental (Caragliu et al., 2011; Carbonera, 2017).

É fundamental a criação da consciência de comprometimento dos cidadãos chapecoenses sobre a necessidade de construção participativa de um projeto de desenvolvimento para a cidade. Projeto esse inteligente, ágil, com potencial de gerar mudanças significativas para as pessoas, na infraestrutura e nos mecanismos utilizados para a tomada de decisão. Isso permite o engajamento e empoderamento dos cidadãos como agentes geradores de mudanças e avanços para o município.

Uma cidade inteligente é constituída por pessoas conscientes do seu papel de agentes transformadores dos espaços, de forma a equalizar as dimensões prudência ecológica, eficiência
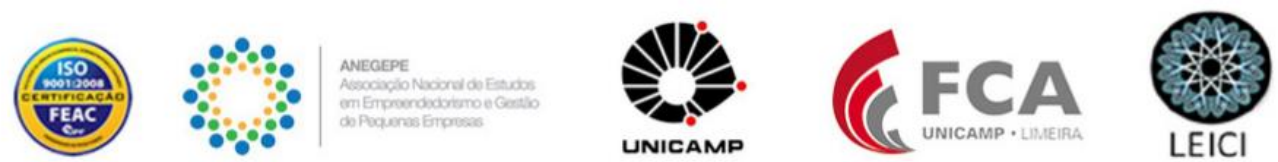
energética e equidade socioespacial (Romero, 2007). Já as cidades criativas estimulam a criação de ideias, consolidam a cultura de conhecimento e inteligência em todos os segmentos da cidade (Landry, 2000). Incentivam a pesquisa, inovação, cultura, economia, tecnologia e a busca de elementos para diferenciá-las de outras cidades. Cidades criativas possuem na sua essência a criatividade, nos indivíduos, empresas, capital, organizações do conhecimento, academia, governo, população escolarizada e produtiva (Fernandes \& Gama, 2012).

A partir do exposto, a problemática que motiva a realização do estudo está associada ao potencial produtivo que Chapecó representa para o Oeste Catarinense, apesar das fragilidades e limitações ao desenvolvimento mais expressivo, associado à necessidade de construir/desenvolver uma cidade inteligente e criativa. Os aspectos conceituais inspiram a proposição de algumas questões: Como construir uma cidade inteligente e criativa? O que a cidade já possui e se alinha às premissas de cidade inteligente e criativa? O que falta para Chapecó se tornar inteligente e criativa? Diante disso, o objetivo proposto é verificar os aspectos legais e o ponto de vista de lideranças sobre a perspectiva da formação de uma cidade inteligente e criativa, com base nos pressupostos de Caragliu et al. (2011).

As contribuições da pesquisa estão associadas à análise do processo de formação de Chapecó (SC) como cidade inteligente e criativa, a partir das determinações legais e da percepção dos diferentes atores locais. Justifica-se a utilização da legislação municipal pela associação necessária da pesquisa com o amparo legal e, pelo significativo aporte no processo de desenvolvimento urbano, com influência decisiva no futuro da cidade e que implica nas condições de vida da população. Com relação aos diferentes atores ouvidos, a pesquisa aportou para o ponto de vista de cidadãos aptos a efetuar uma leitura da realidade de Chapecó e indicar tendências para o desenvolvimento urbano.

Por fim, além desta introdução, o artigo apresenta na sequência seções que expõem: os aspectos teóricos alusivos às cidades inteligentes e criativas, o procedimento metodológico, a análise dos resultados, as considerações finais e as referências utilizadas.

\section{Cidades inteligentes e criativas}

$\mathrm{O}$ crescente processo de urbanização levou mais da metade da população mundial a viver em cidades, centros de influência socioeconômica, simultaneamente, a revolução digital tem criado uma sociedade altamente conectada (Cunha et al., 2016). Da combinação destas ocorrências, surgem as discussões sobre cidades inteligentes e criativas, centros urbanos colaborativos e conectados com um objetivo comum; integrar pessoas, transformar suas relações e melhorar sua qualidade de vida. As cidades inteligentes e criativas são capazes de tornar as pessoas mais competitivas, mais produtivas, pois é nelas que as pessoas compartilham, disputam, aprendem e criam (Dassen, 2014).

O termo "cidades inteligentes" refere-se a um mecanismo estratégico para o planejamento e gestão inteligente das cidades. Combina atração de capital humano e o uso das Tecnologias de Informação e Comunicação (TIC's) para melhoria da qualidade de vida da população (Closs \& Oliveira 2017). O termo é associado ao emprego eficiente de (TICs) como uma ferramenta para melhorar a infraestrutura e serviços da cidade, que consequentemente passa a ser atrativa aos cidadãos e às empresas, atendendo as necessidades dos diferentes atores. A cidade inteligente preza pela a eficiência dos serviços urbanos e a agilidade nas operações, elementos que geram competitividade e atenuam as assimetrias. $\mathrm{O}$ tema ainda é complexo e mais formal do que funcional (Aieta, 2016), no Brasil é um campo de estudo ainda pouco

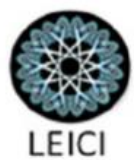


explorado, mas tem relevância global, especialmente na Europa, onde já se denomina como moda no campo político Caragliu et al. (2011).

As diferentes abordagens apontam que não há consenso entre os autores sobre a definição de cidades inteligentes, e menos ainda, quando observado sob diferentes domínios do conhecimento (Meijer \& Bolívar, 2015). Entretanto, há um ponto em comum entre todas as definições, o uso das (TICs). Embora o tema seja amplo, determinados autores apresentam dimensões mínimas que definem o grau de inteligência de uma cidade (Hollands, 2008; Dassen, 2014; Caragliu et al., 2011). Nesta pesquisa aplica-se a categorização baseada em Caragliu et al. (2011) que se utilizam de seis pontos para caracterizar uma cidade inteligente, I) utilização de infraestrutura em rede, maior eficácia econômica; II) cidades orientadas para os negócios, ênfase à atratividade de novos negócios; III) inclusão social, crescimento urbano equitativo, que contribui para a diminuição das assimetrias; IV) indústrias criativas, alto potencial tecnológico para atrair o criativo; V) apelo ao papel do capital social e relacional no desenvolvimento urbano, a comunidade aprende e inova; VI) foco na sustentabilidade social e ambiental, a partir de projetos direcionados.

Cabe ressaltar a possibilidade de uma cidade ser "criada" inteligente, como é o caso de Masdar City, nos Emirados Árabes Unidos (INTELI, 2012), neste caso a cidade já incorpora elementos inteligentes em todas as vertentes, do planejamento à construção. Iniciativas como carbono zero, produção de energia renovável, reciclagem de resíduos, redução do consumo de água e utilização de veículos elétricos ou de transportes públicos, foram alguns dos focos da administração pública de Masdar City. Mas na grande maioria dos casos, as cidades "se tornam" inteligentes, atrelando aos processos usuais de desenvolvimento urbano, elementos estratégicos.

Em boa parte dos países da Europa, as cidades inteligentes fazem parte da agenda pública de gestão, em Portugal foi criada a Rede Smart Cities Portugal (Portugal, 2013), que tem como principais objetivos desenvolver soluções urbanas inovadoras, de forma integrada além de potenciar a participação das empresas nos debates acerca do tema. A Espanha é outro exemplo de cidade que vem "tornando-se" inteligente. Suas ações centram-se na instalação de sensores pela cidade, assim conecta sua população a informação em tempo real. Este projeto prevê também, controle ambiental, gestão de trânsito, sistemas inteligentes nos parques públicos e o uso fontes de energia renováveis em edifícios públicos (Dassen, 2014). Enfim, na literatura internacional são vários os exemplos que protagonizam cidades inteligentes, onde cada qual é figurante de cenários únicos, e embasam assim, suas dinâmicas.

Em 2017 a Unidade de Assessoria Institucional do SEBRAE Nacional publicou um estudo que aponta a classificação das principais cidades inteligentes do mundo (SEBRAE, 2017). Esta pesquisa considerou quatro rankings internacionais: i) City in Motion Index 2016 (CIMI); ii) Global Cities Index 2016 (GCI); iii) Global Power City Index 2016 (GPCI); e iv) Top Ranked Smart Cities 2016 (TRSC). De acordo com a pesquisa, foram selecionadas as cidades classificadas em três ou mais rankings, são elas, Londres, Nova York, Amsterdam, Paris, São Francisco e Singapura. O estudo relaciona também as cidades de Barcelona e Oslo, reconhecidas como referências mundiais.

Transformar cidades tradicionais em cidades inteligentes é relevante e ao mesmo tempo desafiador, pois implica na conscientização da comunidade, instituições e governo do seu papel de agentes transformadores (Romero, 2007). A participação de diferentes atores sociais neste processo é, sem dúvida, indispensável, uma vez que aqueles que vivem nas cidades possuem a
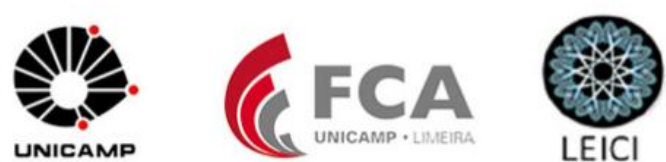
percepção necessária para propor ideias aplicáveis ao seu contexto urbano. Os governos são peças chave e podem influenciar neste processo, pois cabe a estes o planejamento, gerenciamento e governança dos serviços públicos. A maioria, as cidades não têm muitas das condições ideais para que a população possa usufruir de ambientes inteligentes, atrativos e melhores para se viver. Entre as adversidades citam-se os contratempos causados por um modelo urbano segregador, que priorizou a utilização de veículos automotores individuais, conjugadas com a carência de espaços e equipamentos públicos e comunitários.

Mas o Brasil tem despertado para a necessidade de adequar suas cidades ao contexto global, e iniciou em 2017 o desenvolvimento de um projeto-piloto em algumas cidades brasileiras com foco em cidades inteligentes e criativas. O projeto têm sido coordenado pelo SEBRAE Nacional e a referência estudada e aplicada ao projeto-piloto no Brasil é a cidade de Londres, "por apresentar facetas de desenvolvimento em todos os campo apontados como prioritários no desenvolvimento do projeto-piloto brasileiro". Outro caso que poderá em breve ser testado no Brasil é o modelo adotado por Singapura, cidade que se destaca pelas diferenciadas iniciativas de transformação da cidade (SEBRAE, 2017).

Compreendido o contexto de cidade inteligente e admitindo, que um dos focos são as pessoas e a forma como interagem, passa-se a questionar se a cidade inteligente é também uma cidade criativa. Quais seriam os traços de uma cidade inteligente e criativa? Há uma ponte entre inteligência e criatividade? Ao considerar a afirmação de Reis (2011) pode-se considerar que sim, pois inovação nada mais é do que a criatividade posta em prática.

O contexto de cidade criativa está associado ao conceito de economia criativa que originou-se da designação de indústrias criativas (Montag et al., 2012). Assim, a partir dos anos 1990, convencionou-se adotar o termo cidade criativa, para caracterizar as cidades em que a criatividade é elemento essencial do negócio, nos diferentes setores da economia. Entre os autores que se destacaram na investigação deste tema um dos mais renomados foi o britânico Charles Landry, primeiro autor a empregar o termo cidade criativa, em 1995, quando publicou a obra The Creative City, em parceria com Franco Bianchini. As contribuições deste autor se tornaram ainda mais expressivas com suas investigações futuras, especialmente a publicada em 2000 The Creative City: A Toolkit for Urban Innovators (Reis, 2011).

Richard Florida, economista estadunidense, foi o sucessor de Landry nos debates sobre o tema, ele aproximou o termo "economia criativa" da gestão de espaços urbanos, fato este que causou repercussão e controvérsias (Reis, 2011). Sua teoria foi amplamente discutida, pois Florida cria uma nova classe econômica, que chamou de classe criativa. O ponto controverso de sua teoria é a aglomeração da classe criativa, o que causaria ainda mais assimetrias, o autor defende que à medida que a economia cresce, cresce também a concentração de talentos. Sua expressão tem peso quando cita que os Estados Unidos "não tem vantagem na produção de pessoas ou empresas criativas, sua real vantagem reside em sua habilidade para atrair os talentos econômicos de todo o mundo" (Florida, 2005, p. 5). O autor destaca que a tarefa é construir uma comunidade criativa, uma sociedade criativa, não apenas uma economia criativa (Florida, 2003).

O pressuposto é que a sociedade pode fazer coisas extraordinárias (Landry, 2000) basta que sejam instigadas, e oportunizadas. Uma cidade criativa apresenta três características fundamentais: I) capacidade de produzir inovação, não somente tecnológica, mas social; II) conexão, capacidade de desenvolver projetos de mobilidade urbana; e, III) cultura, seja como elemento simbólico ou econômico. Logo, toda e qualquer cidade pode ser criativa, pois a
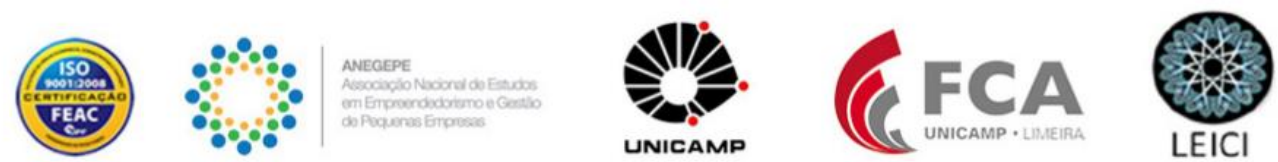
criatividade é um recurso imaterial existente em todas as localidades, independente do estágio de desenvolvimento de suas economias (Florida, 2003; Pardo, 2011; Reis, 2011).

A reflexão destes e demais autores, culminou na elaboração do relatório The Creative Economy Report, publicado em 2010 pela United Nations Conference on Trade and Development (UNCTAD). O documento ressalta a crescente atenção que deve ser dada aos segmentos criativos, devido ao retorno socioeconômico em escala local e global. Segundo o relatório, a criatividade contribui para uma perspectiva de desenvolvimento centrado nas pessoas e é insumo essencial para a constituição de territórios criativos, o que favorece a inclusão social e a diversidade cultural (UNCTAD, 2010).

Salienta-se que as cidades não nascem inteligentes e criativas, com poucas exceções, mas se tornam. É um processo de transição urbana baseada em adaptações e compartilhamento, os líderes políticos têm papel indispensável na configuração da governança urbana Lin (2011) onde inteligência e criatividade não devem ser meramente medidas pelo êxito econômico que proporcionam, mas pelo sentimento de pertencimento de seus moradores. O Quadro 1 apresenta as premissas de uma cidade inteligente e criativa sob o olhar de diferentes autores.

\section{QUADRO 1 - Conceitos elementares de cidades inteligentes e criativas}

\begin{tabular}{|c|c|}
\hline Cidades Inteligentes & Cidades Criativas \\
\hline $\begin{array}{l}\text { Conectividade como principal fonte de } \\
\text { desenvolvimento urbano, infraestrutura em rede para } \\
\text { impulsionar o desenvolvimento (Hollands, 2008). }\end{array}$ & $\begin{array}{l}\text { Um lugar que estimula e incorpora a cultura da } \\
\text { criatividade (Landry, 2000). }\end{array}$ \\
\hline $\begin{array}{l}\text { Conectam de forma inovadora as TIC's, aos aspectos } \\
\text { organizacionais, normativos, sociais e tecnológicos } \\
\text { (Meijer \& Bolívar, 2015). }\end{array}$ & $\begin{array}{l}\text { Precisa ser funcional em três dimensões: talento, } \\
\text { tecnologia e tolerância (Florida, 2005). }\end{array}$ \\
\hline $\begin{array}{l}\text { Expansão do acesso às TIC fator base. Forma cidadão } \\
\text { ativo com espírito de coletividade e colaboração } \\
\text { (Gonçalves \& Paiva, 2015). }\end{array}$ & $\begin{array}{l}\text { Preza pela inovação e transformação. É uma cidade que } \\
\text { se reinventa, que tem identidade cultural (Reis, 2011). }\end{array}$ \\
\hline $\begin{array}{l}\text { Cidades capazes de tornar as pessoas mais competitivas } \\
\text { e consequentemente mais produtivas (Dassen, 2014). }\end{array}$ & $\begin{array}{l}\text { É o motor da nova economia e têm se tornado centro da } \\
\text { política urbana, de forma multidisciplinar (Lin, 2011). }\end{array}$ \\
\hline $\begin{array}{l}\text { Acesso da população à inovação tecnológica que } \\
\text { disponibilize soluções alternativas em relação às } \\
\text { convencionais (Aieta, 2016). }\end{array}$ & $\begin{array}{l}\text { É um território aberto ao risco, seu sucesso depende da } \\
\text { cooperação estratégica dos agentes, capacidade } \\
\text { coletiva, iniciativas privadas e políticas públicas } \\
\text { (Pardo, 2011). }\end{array}$ \\
\hline
\end{tabular}

Fonte: Elaborada pelos autores (2018)

Baseado nestes pressupostos entende-se que para que a cidade seja inteligente e criativa é necessário que haja responsabilidade social integrada, isto é, pública e privada. Cidade inteligente e criativa é aquela que se permite gerar estratégias de melhoria de vida da sua população, a partir de suas próprias potencialidades (Pardo, 2011), portanto, envolve percepções e capacidades individuais e coletivas, reconstrução, adaptabilidade e reinvenção. Parte das características necessita estar contemplada no escopo legislativo de da cidade, que proporciona amparo legal à tomada de decisão em ações vinculadas ao desenvolvimento urbano.

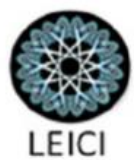




\section{Procedimentos Metodológicos}

O estudo foi realizado na cidade de Chapecó (SC), no intuito de verificar os aspectos legais e o ponto de vista de lideranças sobre a perspectiva da formação de uma cidade inteligente e criativa. A fim de alcançar o objetivo da pesquisa, foi adotada a estratégia de estudo de caso, com abordagem qualitativa, descritiva (Richardson, 2009), a partir da revisão bibliográfica e documental em publicações científicas e legislação municipal. Na sequência, realizou-se a etapa de campo com a aplicação de entrevistas semiestruturadas e posterior análise.

Em síntese, a operacionalização do estudo seguiu as seguintes etapas: definição dos objetivos de pesquisa e abordagem conceitual chave que derivou as categorias utilizadas no estudo; identificação e seleção de documentos da legislação municipal; elaboração do roteiro de entrevista; mapeamento das lideranças chave, com posterior contato telefônico, convite a participarem da pesquisa e agendamento de horário; realização das entrevistas, que tiveram duração total de nove horas e doze minutos; transcrição das entrevistas na íntegra; e, por fim, triangulação e análise de conteúdo (Richardson, 2009) da legislação municipal, das entrevistas e do aporte teórico.

$\mathrm{Na}$ abordagem dos aspectos legais, foram utilizados o Plano Diretor Municipal, o Plano de Mobilidade Urbana e a Lei Municipal de Desenvolvimento Econômico, os quais contemplam e preparam o cenário urbano às cidades inteligentes e criativas. Na sequência, foi verificada a percepção dos atores locais a partir da aplicação de onze entrevistas. A seleção dos entrevistados ocorreu em função da representatividade das instituições nas quais atuam. Eram representantes do executivo e do legislativo municipal, do judiciário, de entidades de classe e sindicais locais, além de liderança comunitária. Por uma questão ética de pesquisa, no intuito de preservar a identidade, foram utilizados codinomes para os entrevistados.

Por fim, a análise de conteúdo foi realizada com base nas categorias definidas a priori, derivadas do estudo de Caragliu, et al. (2011) conforme detalhado no Quadro 2, que apresenta o resumo da metodologia da pesquisa.

QUADRO 2 - Resumo da metodologia da pesquisa

\begin{tabular}{|l|l|}
\hline \multicolumn{1}{|c|}{ Descrição } & \multicolumn{1}{c|}{ Classificação } \\
\hline Abordagem & Qualitativa \\
\hline Tipo de pesquisa & Descritiva \\
\hline Classificação quanto aos procedimentos & Estudo de caso \\
\hline & $\begin{array}{l}\text { Documentos: PDM, PMU e LMDE. } \\
\text { Entrevistas semiestruturadas. }\end{array}$ \\
& $\begin{array}{l}\text { Codinomes dos entrevistados: } \\
\text { LC - Líder Comunitário; SRP- Sindicato Rural Patronal } \\
\text { RU - Reitor de Universidade; SC - Sindicato do Comércio da } \\
\text { Método de coleta dos dados } \\
\text { Região de Chapecó; CO- Cooperativa; CD - Câmara dos } \\
\text { Dirigentes Lojistas; MP - Ministério Público; SRL - Sindicato } \\
\text { Rural Laboral; CV - Câmara de Vereadores; AC - Associação } \\
\text { Comercial e Industrial de Chapecó; EM - Executivo } \\
\text { Municipal }\end{array}$ \\
\hline Técnica de tabulação dos dados & $\begin{array}{l}\text { Tabelas } \\
\text { Quadros } \\
\text { Seleção de aspectos legais relacionados ao assunto } \\
\text { Transcrição das abordagens dos entrevistados }\end{array}$ \\
\hline
\end{tabular}




\begin{tabular}{|l|l|}
\hline Técnica de análise & Análise de conteúdo \\
\hline & $\begin{array}{l}\text { Derivadas do estudo de Caragliu, et al., (2011) } \\
\text { - infraestrutura em rede } \\
\text { Categorias de análise } \\
\text { - cidades orientadas para negócios } \\
\text { - inclusão social } \\
\text { - indústrias criativas } \\
\text { - papel do capital social e relacional no desenvolvimento } \\
\text { - sustentabilidade social e ambiental }\end{array}$ \\
\hline
\end{tabular}

Fonte: Elaborado pelos autores (2018).

\section{Resultados e Discussão}

Inicialmente, são trianguladas as informações da legislação municipal de Chapecó (SC) e a base teórica. Na sequência, a análise é centrada na compreensão dos elementos do espaço urbano, com base no ponto de vista dos cidadãos entrevistados, alinhada à categorização estabelecida a priori.

\subsection{A Legislação Municipal como Estratégia à Formação de Cidades Inteligentes e Criativas}

A legislação municipal analisada possui relação direta com as dimensões de desenvolvimento aportadas no estudo e expressa as diretrizes futuras do ambiente urbano e municipal. Na análise, utilizou-se do Plano Diretor Municipal (PDM) (Chapecó, 2014); Plano de Mobilidade Urbana (PMU) (Chapecó, 2016) e Lei Municipal de Desenvolvimento Econômico de Chapecó (LMDE) (Chapecó, 1999).

As características legais são indicativas das perspectivas de desenvolvimento da cidade inteligente e criativa. Logo, o PDM expressa a função social da cidade e da propriedade, subordinada ao interesse coletivo, demandas econômicas e sociais. Os principais componentes da função social são: infraestrutura em rede e serviços públicos para todo o território; direito à mobilidade, ao transporte coletivo e individual, à acessibilidade universal, ao saneamento ambiental e à participação da sociedade nas decisões da política urbana (Chapecó, 2014; 2016). Isso compõe as estratégias também postuladas por Zipori \& Cohen (2015) como oportunidade para um novo desenvolvimento urbano e territorial.

O PDM prevê a descentralização das atividades econômicas com vistas a novos polos de serviços, empregos e rendas que promovam o desenvolvimento econômico dos bairros e regiões da cidade (Chapecó, 2014; 2016). Busca contribuir com o bem-estar social, promover maior equilíbrio urbano em função da diversificação de atividades econômicas mais próximas do local de moradia, geração de trabalho, renda e laços de solidariedade espacial. Portanto, uma cidade mais equilibrada orienta-se para os negócios não apenas na área central e sim, formando polinúcleos de inovação industrial e demais atividades criativas (Caragliu et al., 2011).

No intuito de aperfeiçoar a utilização da infraestrutura em rede, o PDM condiciona a implantação e expansão das atividades econômicas ao respeito ao ambiente natural, à infraestrutura disponível e às condições de mobilidade e conectividade adequadas (Chapecó, 2014; 2016), contribuindo para a diminuição das dissimetrias urbanas, de modo a integrar socialmente os cidadãos. Isso vai ao encontro da conexão e da mobilidade como pressupostos da cidade criativa e inteligente (Florida, 2003; Pardo, 2011; Reis, 2011).

O PDM apresenta ainda diretrizes de desenvolvimento prioritário em função das vocações, tipologias, e tendências econômicas no município, como a orientação para os
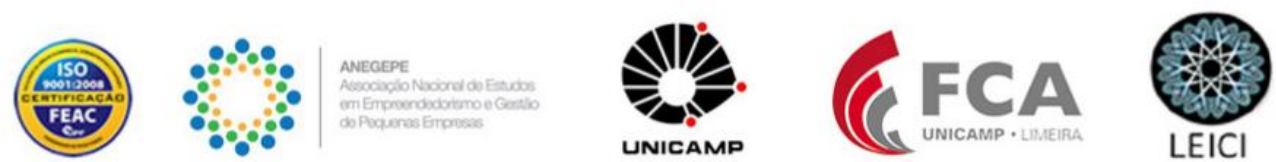
negócios (Caragliu et al., 2011; Chapecó, 2014) e política focada na implantação, expansão e reativação de empreendimentos de diferentes setores (Chapecó, 1999). Destacam-se as atividades aptas a se instalarem em área de parque científico e tecnológico destinado às empresas, centros públicos e privados de pesquisa, desenvolvimento e inovação, prestadores de serviços de base e de apoio às atividades tecnológicas (Chapecó, 2014). Isso pode contribuir com o adensamento urbano, representando um mecanismo de inovação e diversificação das cadeias de produção consolidadas e favorecer a cristalização de uma cidade inteligente e criativa, independente do estágio de desenvolvimento da sua economia (Florida, 2003; Pardo, 2011; Reis, 2011).

A diversidade de atividades econômicas desenvolvidas é também reflexo da capacidade empreendedora existente em Chapecó. Esse fator promoveu a alteração nos padrões das atividades econômicas instaladas/projetadas, muitas oriundas da aliança de grupos empresariais e de novos empreendedores (cidade policêntrica). Em consonância, o PDM e a LMDE prospectam estímulo e apoio ao empreendedorismo, às micro e pequenas empresas, às atividades da economia solidária, cooperativismo, associativismo e atividades de base tecnológica, desde que se estabeleçam nas regiões com maiores demandas de investimentos em função da segregação urbana (Chapecó, 1999; 2014). Isso reforça a característica de cidade orientada para negócios (Caragliu et al., 2011).

Quanto ao estímulo à implantação de atividades inovadoras, o PDM induz à área urbana com maior fragilidade ecológica, uma vez que abriga a bacia hidrográfica fornecedora de recursos hídricos para a cidade. Atribui uma destinação "prioritária à promoção de atividades econômicas, científicas, tecnológicas de ensino e inovação e ao desenvolvimento dos bairros e agrupamentos urbanos, priorizando a conservação ambiental dos potenciais hídricos" (Chapecó, 2014, p. 33). Índices construtivos menos severos contribuem para a sustentabilidade ambiental urbana a partir da manutenção do abastecimento de água e distribuição de áreas verdes de forma progressiva e aferem qualidade ambiental urbana, (Caragliu et al., 2011).

Outro indicador municipal, o capital social e relacional, está vinculado à capacidade de articulação entre as diferentes instâncias representativas da sociedade. Em Chapecó, além de outras instâncias de governança conjugada, existe a gestão urbana e territorial por meio dos instrumentos de participação popular como consultas e audiências públicas e a conferência da cidade (Chapecó, 2014). Aqui, o Conselho da Cidade representa um dos ambientes de decisão com participação popular.

As cidades que apresentam vitalidade econômica são ambientes que atraem a população regional, o que aumenta também às demandas locais por políticas sociais de bem-estar, tais como, a habitação. O PDM e o PMU contemplam a política de desenvolvimento urbano sobre as áreas de lazer, atividades culturais, esportivas e de convívio social. São previstas áreas para fins de habitação de interesse social que incluam equipamentos sociais, espaços públicos, serviços e comércio de caráter local. Prioriza a acessibilidade a pessoas com deficiência ou mobilidade reduzida, pedestres, ciclistas e transporte coletivo, tornando-se assim, ambientes de integração e sustentabilidade social. A urbanização pode, inclusive, ser simplificada e progressiva, representando oportunidade de estímulo ao capital social e relacional (Caragliu et al., 2011).

Ainda no contexto das cidades criativas e inteligentes, é relevante a formação de uma rede de cidades, com laços de solidariedade em nível regional, o que contribui para reduzir assimetrias e difundir oportunidades de serviços aos ambientes menos privilegiados - pequenos

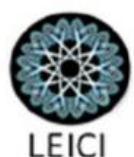


municípios. Assim, o PDM possui conformidade com a função de centro regional exercida por Chapecó, com potencialidade para diversificação das atividades econômicas e aproveitamento dos fatores de atração de novas cadeias produtivas. Diante disso, verificou-se a ascensão do setor de serviços em Chapecó nas atividades de saúde, educação - da formação básica ao doutorado - suporte para a construção civil, serviços públicos, de logística e terceirizados, complementando as principais cadeias de produção da região.

Por fim, as legislações municipais expressam as diretrizes de desenvolvimento futuro para Chapecó. No entanto, necessitam ser aplicadas, implementadas, geridas e fiscalizadas. Isso que destaca a importância da governança compartilhada para a ampliação dos processos que contemplam políticas de desenvolvimento inovadoras e criativas. A cidade inteligente e criativa é também resultado de um processo histórico construído continuamente em diferentes temporalidades, tendo a legislação relevante papel na construção dos elementos que contribuem para a qualidade de vida das pessoas na cidade.

\subsection{Percepção dos Agentes Locais sobre a Formação de Cidades Inteligentes e Criativas}

A análise está centrada na compreensão de elementos vinculados ao espaço urbano de Chapecó, com base no ponto de vista dos cidadãos entrevistados. Alinha-se às categorias estabelecidas a priori com base em Caragliu et al. (2011), complementadas pela literatura baseada em Florida (2003); Pardo (2011) e Reis (2011).

Sobre a infraestrutura em rede na cidade, que engloba serviços empresariais, habitação, lazer, serviços de estilo de vida e TICs (Caragliu et al., 2011), a fala dos entrevistados (LC; MP; SRP; CV; SRL; AC; CO, 2017) destacou algumas necessidades de melhorias em locais de habitação de interesse social desconectados do ambiente urbano, de forma que a inclusão social seja completa. É adequado e necessário que redes de serviços básicos, como creches, escolas, segurança pública e áreas de lazer, sejam implementadas com eficiência, pois condicionam a qualidade de vida dos cidadãos.

Deficiências da infraestrutura em processos de expansão urbana foram observadas por LC, que destacou a ausência das redes de esgoto sanitário e de fluxos de telecomunicações, mesmo em ambientes providos de comércio e serviços, como universidades e demais atividades econômicas. Tais infraestruturas tendem a ser disponibilizadas após a instalação das edificações, o que representa desconformidade com as determinações legais. A carência de infraestrutura também é elemento limitador da hibridação urbana necessária para promover a descentralização do desenvolvimento, o que torna os bairros mais autônomos, menos dependentes da área central da cidade (CO, 2017). A conexão e mobilidade urbanas são fundamentais na promoção de uma cidade inteligente e criativa (Florida, 2003; Caragliu et al., 2011; Pardo, 2011; Reis, 2011).

Não obstante as críticas quanto aos riscos de se atribuir peso excessivo ao valor econômico como único motor do desenvolvimento urbano, as cidades orientadas para os negócios apresentam um melhor desempenho socioeconômico (Caragliu et al., 2011). Nessa direção, Chapecó tem a presença de empreendedores e empresas inovadoras e economia diversificada. Para PM e PE, a cidade é receptiva para negócios com base em cooperação empresarial, abrangendo diferentes padrões de consumo. Os entrevistados também ressaltam a ampliação de serviços inovadores, como eventos de lazer e entretenimento. Isso tudo reforça a aptidão da cidade para novos negócios (Caragliu et al., 2011).
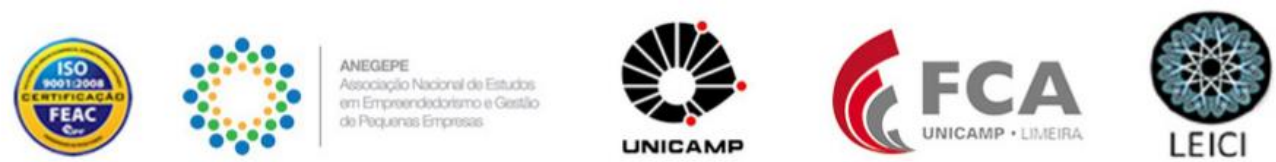
A cidade inteligente também exige um crescimento urbano equitativo e no qual os cidadãos alcancem a inclusão social em serviços públicos (Caragliu et al., 2011), o que requer uma rede para a tomada de decisão e destaca a importância dos órgãos gestores. Em Chapecó, $\mathrm{CV}$ afirma que os processos participativos são pontuais e não permanentes e consolidados. Entretanto, CV destaca como característica positiva a disponibilidade dos grupos sociais se organizarem nos processos de participação social, empoderamento e governança compartilhada. O MP observa que "em Chapecó as pessoas sentem que são atores vivos do processo de modernização e crescimento da cidade", o que se deve ao contexto cultural regional de proximidade entre os cidadãos. O "espírito cooperativo" reflete-se na dinamicidade e nos padrões das atividades econômicas (SRP, 2017).

A literatura aponta ainda a importância da adequada consideração ao capital social e relacional no desenvolvimento urbano para evitar a polarização econômica, espacial e cultural (Caragliu et al., 2011). Dessarte, o MP destaca a participação social como processo de aprendizagem contínua, motivadora da maior participação a partir do momento em que o cidadão cria a rotina de participar. Assim, há um potencial para a ampliação de uma "perspectiva colegiada para o gerenciamento de políticas públicas" (CV, 2017), o que representaria um avanço institucional de participação social e gestão compartilhada em níveis ainda não alcançados. Isso vai ao encontro da capacidade da comunidade aprender, adaptar e inovar como requisito da cidade inteligente (Coe et al., 2001). Estende-se à administração pública a oportunidade de inovação nos processos e redução da estrutura gerencial, desburocratizando-se por meio da sistemática modernização das TIC's (SC, 2017). Isso conforma-se com a perspectiva de cidade criativa quanto à capacidade de produzir inovação (Florida, 2003; Pardo, 2011; Reis, 2011).

Quanto às indústrias criativas, na determinação de uma cidade inteligente, incorporam as atividades econômicas com forte dependência de propriedade intelectual (UNCTAD, 2010). Assim, as empresas se orientam para atrair o criativo (Florida, 2005). RU destaca que Chapecó precisa planejar alternativas de desenvolvimento às atuais cadeias de produção, motivar novas forças econômicas com base na economia criativa, na cultura da inovação e na indústria 4.0. É crucial minimizar a importância das atuais commodities como principal recurso econômico e investir em soluções criativas, de maior valor agregado, mais tecnologia, inclusão social, sustentabilidade ambiental e qualidade de vida para a população (RU, 2017). Nesse sentido, as instituições de ensino superior e stricto sensu são indutoras do desenvolvimento por meio de pesquisas em inovação e na formação do polo tecnológico - embrionário -, na drenagem de profissionais capacitados para outros ambientes regionais e nos serviços alternativos às cadeias de produção tradicionais - agroindústria e metalomecânica (MP; SRP; AC; CD; CD, 2017).

Quanto à sustentabilidade social e ambiental, é o principal componente estratégico das cidades inteligentes, devido aos limitados recursos diante do crescimento das cidades (Caragliu et al., 2011). Reforça-se a necessidade do equilíbrio entre o crescimento e a proteção aos mais fracos. Neste sentido, um condicionante desafiador em Chapecó diz respeito aos grupos familiares de catadores de resíduos urbanos recicláveis. O MP e CO relatam que a parceria entre entidades públicas e privadas busca promover o empoderamento necessário à formalização e implementação de práticas ambientais e de saúde adequadas aos envolvidos. Outra questão sobressalente refere-se às dificuldades de aproximação e integração dos grupos de cultura indígena (Terra indígena Condá e Toldo Chimbangue) do município aos demais grupos sociais. Contudo, o MP ressaltou a valorização das escolas em língua autóctone e o potencial para um
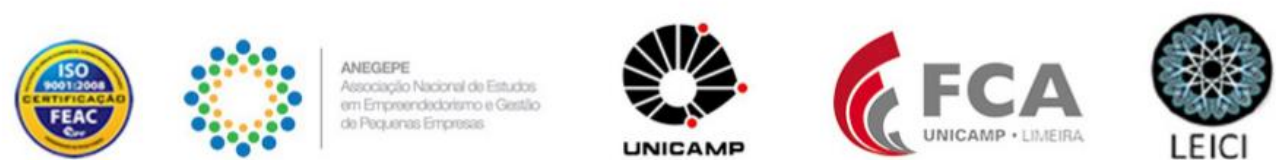
museu da cultura indígena regional (ainda não edificado) com base nos povos Kaingang e Guarani instalados em Chapecó.

No quesito sustentabilidade ambiental, as cidades médias tendem a ampliar as demandas por serviços, como consumo de água, pelo aumento da população e diversificação das atividades econômicas no setor industrial. Reside aí outro tema complexo, que diz respeito ao ordenamento do uso do solo para fins residenciais e para atividades econômicas na bacia de captação de água de Chapecó (AC, 2017). AC relata preocupação com a capacidade atual e a continuidade do abastecimento de água no espaço urbano. Esta questão permanece em aberto e suscita inúmeros embates velados entre diferentes grupos de interesses públicos e privados, da academia e do empresariado.

Isso posto, para a materialização de cidades inteligentes e criativas, além das manifestações expostas, os entrevistados abordaram: a inclusão de detentos por meio de instituições de ensino superior e empresas na penitenciária; a infraestrutura de redes móveis de telecomunicações em ambientes públicos destinados ao lazer, visando à promoção de uma cidade humanizada e inclusiva; e, a criação de aplicativo para comunicação instantânea de problemas urbanos entre os cidadãos e os gestores públicos municipais, tornando mais ágeis os processos de tomada de decisão.

Por fim, a partir da triangulação da legislação municipal, entrevistas e aporte teórico, elaborou-se a síntese das principais demandas (o que falta) e evidências (o que possui) para Chapecó como cidade inteligente e criativa, exposta no Quadro 3.

\begin{tabular}{|c|c|c|}
\hline $\begin{array}{l}\text { Premissas } \\
\text { Caragliu et } \\
\text { al. }(\mathbf{2 0 1 1})\end{array}$ & Demandas ( o que falta) & Evidências ( o que possui) \\
\hline $\begin{array}{l}\text { Utilização } \\
\text { de } \\
\text { infraestrutu } \\
\text { ra em rede }\end{array}$ & $\begin{array}{l}\text { - maior integração espacial e de infraestrutura } \\
\text { em setores que abrigam a população de baixa } \\
\text { renda; } \\
\text { - criação de novos espaços públicos para o } \\
\text { entretenimento e lazer; } \\
\text { - construção do contorno viário para melhorar } \\
\text { a mobilidade precária em determinados } \\
\text { setores urbanos; } \\
\text { - acessibilidade universal pelo passeio } \\
\text { público em áreas não centrais; } \\
\text { - rede de conexões universais voltadas a uma } \\
\text { política de desenvolvimento da cidade; } \\
\text { - integração de ferramentas digitais de acesso } \\
\text { às informações e tomada de decisão para a } \\
\text { modernização do poder público; }\end{array}$ & $\begin{array}{l}\text { - definição estratégica na legislação da } \\
\text { mobilidade e desenvolvimento } \\
\text { socioeconômico, oriunda da participação do } \\
\text { capital social no processo de construção, em } \\
\text { conformidade com o Estatuto da Cidade; } \\
\text { - plano diretor direcionado à descentralização } \\
\text { dos negócios para polinúcleos em bairros de } \\
\text { entorno; } \\
\text { - planejamento da continuidade urbana e da } \\
\text { conectividade do sistema viário atual e futuro; } \\
\text { - padronização da acessibilidade na área urbana } \\
\text { central; } \\
\text { - expansão do ensino para o stricto sensu com } \\
\text { eventos nacionais e internacionais de ensino, } \\
\text { pesquisa extensão; }\end{array}$ \\
\hline $\begin{array}{l}\text { Cidade } \\
\text { orientada } \\
\text { para os } \\
\text { negócios }\end{array}$ & - formalização das atividades clandestinas; & $\begin{array}{l}\text { - ênfase em feiras nacionais e internacionais } \\
\text { (Mercoagro, Mercoláctea, Mercomóveis); } \\
\text { - eventos esportivos nacionais que estimulam o } \\
\text { turismo esportivo; }\end{array}$ \\
\hline $\begin{array}{c}\text { Inclusão } \\
\text { social }\end{array}$ & $\begin{array}{l}\text { - dificuldade de integração da cultura } \\
\text { indígena e de imigrantes de outras etnias aos } \\
\text { demais grupos sociais; }\end{array}$ & $\begin{array}{l}\text { - inúmeras instituições de ensino superior, } \\
\text { públicas e privadas, que contribuem na } \\
\text { formação e desenvolvimento das pessoas; } \\
\text { - apoio municipal às associações de catadores de } \\
\text { resíduos urbanos recicláveis; }\end{array}$ \\
\hline
\end{tabular}




\begin{tabular}{|c|c|c|}
\hline & & $\begin{array}{l}\text { - integração de detentos ao processo formal de } \\
\text { ensino e trabalho; } \\
\text { - incentivo à diversidade étnica e inclusão social } \\
\text { dos imigrantes; }\end{array}$ \\
\hline $\begin{array}{l}\text { Indústrias } \\
\text { criativas }\end{array}$ & $\begin{array}{l}\text { - investimentos em tecnologias em espaços } \\
\text { públicos que otimizem a conectividade da } \\
\text { população com o poder público e } \\
\text { intensifiquem a participação social; } \\
\text { - investimentos em aplicativos para facilitar a } \\
\text { vida das pessoas no trânsito, mobilidade } \\
\text { urbana, doação de objetos, voluntariado; } \\
\text {-investimentos no desenvolvimento e atração } \\
\text { de talentos criativos e indústrias culturais; } \\
\end{array}$ & $\begin{array}{l}\text { - associação de Artesãos com } 253 \text { associados, } \\
\text { congregada em } 6 \text { grupos, inclusive índios; } \\
\text { - diversificação de oportunidades de trabalho e } \\
\text { renda em atividades de inovação centradas nos } \\
\text { serviços especializados de ensino, saúde e } \\
\text { suporte ao agronegócio; }\end{array}$ \\
\hline $\begin{array}{c}\text { Apelo ao } \\
\text { papel do } \\
\text { capital } \\
\text { social e } \\
\text { relacional } \\
\text { no } \\
\text { desenvolvi } \\
\text { mento }\end{array}$ & $\begin{array}{l}\text { - formação de novas lideranças urbanas; } \\
\text { - prover tecnologias e estímulos à } \\
\text { participação social da população em geral na } \\
\text { gestão compartilhada de políticas públicas; } \\
\text { - incentivo ao comunitarismo urbano; }\end{array}$ & $\begin{array}{l}\text { - associações, sindicatos e lideranças de } \\
\text { diferentes categorias são engajados e atuantes } \\
\text { na promoção do desenvolvimento local; } \\
\text { - observatório social para monitorar contas } \\
\text { públicas municipais e transparência no uso dos } \\
\text { recursos públicos; }\end{array}$ \\
\hline $\begin{array}{l}\text { Foco na } \\
\text { sustentabili } \\
\text { dade social } \\
\text { e ambiental }\end{array}$ & $\begin{array}{l}\text { - manutenção insuficiente dos espaços } \\
\text { públicos de interação e convívio social; } \\
\text { - expansão dos sistemas de saneamento } \\
\text { básico para todo o tecido urbano; } \\
\text { - incentivos fiscais para empresas e pessoas } \\
\text { físicas investirem em energias limpas } \\
\text { (energia solar, ciclos fechados de água, } \\
\text { reaproveitamento dos resíduos, veículos } \\
\text { elétricos); } \\
\text { - ampliação da rede de água potável e } \\
\text { pavimentação de vias nas comunidades } \\
\text { rurais; } \\
\text { - investimentos em veículos elétricos } \\
\text { públicos; } \\
\text { - necessidade de aumento das áreas com } \\
\text { concentração de vegetação no espaço urbano; } \\
\text { - preservação dos mananciais hídricos que } \\
\text { abastecem a cidade. }\end{array}$ & $\begin{array}{l}\text { - projeto de inclusão para pessoas da terceira } \\
\text { idade: "Cidade do Idoso"; } \\
\text { - investimentos em parques e praças públicas } \\
\text { para interação social, convívio e prática de } \\
\text { esportes. }\end{array}$ \\
\hline
\end{tabular}

Fonte: Elaborado pelos autores com base na pesquisa (2018).

\section{Considerações Finais}

No intuito de verificar os aspectos legais e o ponto de vista de lideranças de Chapecó (SC) sobre a formação de uma cidade inteligente e criativa, analisou-se a perspectiva teórica, legal e a percepção dos atores sociais locais de diferentes esferas públicas e privadas.

A cidade inteligente e criativa incorpora alguns elementos principais como orientação para os negócios, infraestrutura em rede, inclusão social e crescimento urbano equitativo, atratividade de indústrias criativas, apelo ao capital social e relacional, sustentabilidade socioambiental, capacidade de inovação, conexão e cultura. Nesse sentido, identificou-se o que falta, assim como as evidências do que a cidade já possui e se alinha às premissas de cidade inteligente e criativa.

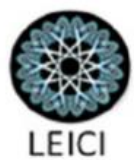


Constatou-se que Chapecó (SC) possui diretrizes para a criação de uma cidade inteligente e criativa. Todavia, há demandas por investimento em cultura, inovação e sustentabilidade socioambiental para consolidar as ações em curso e dar maior conectividade, mobilidade e criatividade aos espaços públicos (Pardo, 2011; Reis, 2008). Também há oportunidades de melhoria em investimentos na inovação arquitetônica, no comunitarismo urbano e nas indústrias culturais (Landry, 2000).

Sobretudo, para Chapecó tornar-se inteligente e criativa é preciso construir um modelo conexionista e descentralizado. Promover a maior participação dos cidadãos, por meio de TIC's e dispositivos inteligentes, o que favorece a construção de políticas públicas e a tomada de decisão a partir das necessidades e desafios de cada policentro da cidade. Um modelo de governança participativa, colaborativa e com transparência, demanda a existência de uma cidade com maior equidade no seu território, com infraestrutura desenvolvida nos diferentes setores (área central, bairros e ambiente rural), com mobilidade de pessoas e agilidade no fluxo dos produtos.

Assim, são necessárias melhorias na infraestrutura, na qualidade das conexões e rede de informações, na integração urbana, rural e regional. Essas exigências aplicam-se às diferentes espacialidades, tornando a cidade mais simétrica na sustentabilidade ambiental e social. É necessário ainda, complementar a organização da cidade com a interconexão dos sistemas existentes no comércio, transporte, administração pública, infraestrutura, saúde, trabalho, educação e meio ambiente (Jordão, 2016).

Os aspectos positivos da cidade referem-se às interconexões entre as instituições, as lideranças comunitárias e os gestores públicos, a partir de pactos em prol do desenvolvimento municipal e regional; neste caso se considera a rede de cidades como elemento catalisador do desenvolvimento. Isso vai ao encontro da afirmação de Pardo (2011): o sucesso vincula-se à cooperação estratégica dos agentes.

Outro aspecto diz respeito ao desenvolvimento que advém da capacidade de adaptabilidade da cidade para a orientação a novos negócios. Isso possibilita que o desenvolvimento urbano e a geração de renda aconteçam prioritariamente pelo viés da produção econômica, não pela transferência de renda advinda de programas sociais. Nesse ínterim, Chapecó tem apresentado uma série de atividades centradas nos segmentos que complementam as atuais atividades do agronegócio (agroindústria) e serviços especializados, o que determina a qualificação econômica e social urbana da cidade.

Por fim, ressalta-se que a transição de Chapecó para uma cidade inteligente e criativa é um processo ainda em curso e embrionário. Isso porque existem demandas estruturais, culturais, sociais, econômicas, institucionais e ambientais a serem atendidas (Caragliu et al., 2011). No entanto, a gênese da capacidade de adaptação do tecido urbano e de suas organizações representa uma fase significativa de mudanças que se estruturam como indicativas da melhoria no bem-estar social dos cidadãos chapecoenses.

Ademais, os pesquisadores fazem constar como limitação da pesquisa o eventual viés decorrente da opção por desenvolver as análises centradas nos estudos de Caragliu et al. (2011). Todavia, guiar as análises com base em uma referência chave permite desenvolver o estudo assumindo uma diretriz. Outra limitação foi a realização de entrevistas com número restrito de lideranças e um corte transversal que retrata a percepção de atores específicos. Entretanto, toda escolha metodológica envolve pontos fortes e fracos, aqui assumidos pelos pesquisadores.
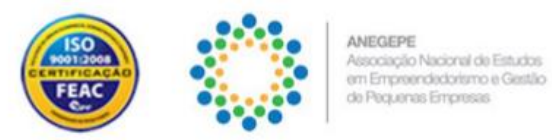

Realizadores:
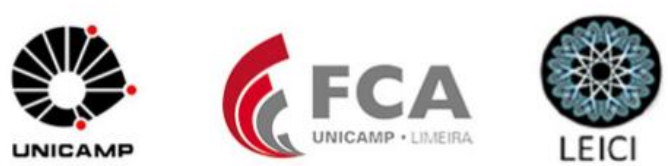
Diante desses resultados, expande-se a possibilidade de pesquisa futura que aborde o desenvolvimento de Chapecó partindo da investigação dos eventos históricos decisivos à ascensão como cidade polo regional, mapeando líderes partícipes da trajetória e incluindo a análise de indicadores socioeconômicos.

\section{Referências}

Aieta, S. A. (2016). Cidades inteligentes: uma proposta de inclusão dos cidadãos rumo à ideia de "cidade humana". Revista de Direito da Cidade, 1622-1643.

https://dx.doi.org/10.12957/rdc.2016.25427.

Caragliu, A., Del Bo, C., \& Nijkamp, P. (2011). Smart Cities in Europe. Journal of Urban Technology, 65-82. https://dx.doi.org/10.1080/10630732.2011.601117.

Carbonera, M. (Org.) (2017). Chapecó 100 anos: histórias plurais (1a ed., Vol. 1). Chapecó (SC): Argos.

Chapecó (Prefeitura municipal). (1999, 16 de dezembro). Lei n. 4093, de 16 de dezembro de 1999. Altera normas referente à Política Municipal de Desenvolvimento Econômico e relativas ao Conselho Municipal de Desenvolvimento Econômico e ao Fundo Municipal de Desenvolvimento Econômico e dá outras providências. Chapecó (SC). Recuperado em 17 de junho de 2017, de https://leismunicipais.com.br/a/sc/c/chapeco/leiordinaria/1999/410/4093/lei-ordinaria-n-4093-1999-altera-normas-referente-a-politicamunicipal-de-desenvolvimento-economico-e-relativas-ao-conselho-municipal-dedesenvolvimento-economico-e-ao-fundo-municipal-de-desenvolvimento-economico-e-daoutras-providencias.

Chapecó (Prefeitura municipal). (2014, 26 de novembro). Lei complementar n. 541, de 26 de novembro de 2014. Aprova o Plano Diretor de Chapecó- PDC. Chapecó (SC). Recuperado em 17 de junho de 2017 de https://leismunicipais.com.br/a1/sc/c/chapeco/leicomplementar/2014/55/541/lei-complementar-n-541-2014-aprova-o-plano-diretor-dechapeco-pdc?q=541.

Chapecó (Prefeitura municipal). (2016, 14 de março). Lei n. 6847, de 14 de março de 2016. Institui o Plano Municipal de Mobilidade Urbana de Chapecó e dá outras providências. Chapecó (SC). Recuperado em 17 de junho de 2017, de https://leismunicipais.com.br/a1/sc/c/chapeco/lei-ordinaria/2016/685/6847/lei-ordinaria-n6847-2016-institui-o-plano-municipal-de-mobilidade-urbana-de-chapeco-e-da-outrasprovidencias? $\mathrm{q}=$ mobilidade $\% 20$ urbana.

Closs, L, \& Oliveira, S. R. (2017). Economia criativa e territórios usados: um debate baseado nas contribuições de Milton Santos. Cadernos EBAPE.BR, 15(2), 349-363.

https://dx.doi.org/10.1590/1679-395152437. 
Cunha, M. A; et al (2016). Smart Cities: transformação digital de cidades. Recuperado em 14 de janeiro de 2018, de

http://ceapg.fgv.br/sites/ceapg.fgv.br/files/u60/smart_cities_bra_versao_final.pdf.

Dassen, T. (2014). Cidades inteligentes: novos agentes de mudança? Recuperado em 02 de janeiro de 2017, de http://www.kas.de/wf/doc/19047-1442-5-30.pdf.

Fernandes, R; \& Gama, R. (2012). A criatividade territorial em Portugal: dos indicadores aos territórios criativos. Recuperado em 14 de janeiro de 2017, de https://estudogeral.sib.uc.pt/bitstream/10316/20845/1/Artigo_Fernandes\%26Gama_PLURIS2 012_Criatividade_VERS\%C3\%83OFINAL.pdf.

Florida, R. (2003). The Rise of the creative class. New York: Basic Books.

Florida, R. (2005). Flight of the creative class: the new global competition talent. New York: Harper Collins.

Hollands, R.G. (2008). Will the real smart city please stand up? Intelligent, progressive or entrepreneurial? Revista City, 303-320. https://dx.doi.org/10.1080/13604810802479126.

Golçalves. R; \& Paiva, A. (2015). Fundação Getúlio Vargas: projetos. Recuperado em 26 de janeiro de 2017, de

http://fgvprojetos.fgv.br/sites/fgvprojetos.fgv.br/files/artigo_robson_smart_cities.pdf.

Instituto Brasileiro de Geografia e Estatística - IBGE. (2017). Estimativa populacional de 2017. Recuperado em 26 de janeiro de 2017, de

http://www.ibge.gov.br/home/presidencia/noticias/imprensa/ppts/0000000402.pdf.

Empresa de Inteligência e Inovação dedicada ao projeto das Cidades Inteligentes - INTELI (2012). Índice de Cidades Inteligentes Portugal. Recuperado em 27 de janeiro de 2017, de http://www.inteli.pt/uploads/documentos/documento_1357554966_2590.pdf.

Landry, C. (2000). The Creative City. Londres: Earthscan Publications Ltda.

Lin, C.C.R. (2011). Cidades criativas e governança urbana: A história de duas cidades em Tai Wan: Taipei e Kaohsiung. In: Reis, A.C.F \& Kageyama, P. (Org). Creative City Perspectives (1a ed., p. 150-161). São Paulo: Garimpo de Soluções e Creative City Productions.

Meijer, A., \& Bolívar, M. P. R. (2015) Governing the smart city: a review of the literature on smart urban governance. International Review of Administrative Sciences, 392-408. https://dx.doi.org/101177/002085231464308.

Montag, T., Maertz, C. P., \& Baer, M. A. (2012) Critical analysis of the workplace creativity criterion space. Journal of Management, 1362-1386.

https://dx.doi.org/10.1177/0149206312441835.

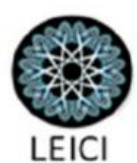


Pardo, J. (2011). Gestão e governança nas cidades criativas. In: Reis, A.C.F; Kageyama, P. (Org). Creative City Perspectives (1a ed., p. 84-93). São Paulo: Garimpo de Soluções e Creative City Productions.

Portugal. (2013). Conferência Cidades Sustentáveis 2020. Lisboa. Recuperado em 07 de janeiro de 2017, de http://www.ccdr-lvt.pt/pt/conferencia-internacional---cidades-sustentaveis-2020/7952.htm.

Reis, A. C. F. \& Kageyama, P. (Org). (2011). Creative City Perspectives (1a ed., Vol. 1). São Paulo: Garimpo de Soluções e Creative City Productions.

Richardson, R. J. (2009). Pesquisa social: métodos e técnicas (3a ed., Vol. 01). São Paulo: Atlas.

Romero, M. A. B. (2007). Frentes do Urbano para a Construção de Indicadores de Sustentabilidade Intra Urbana. Paranoá: cadernos de arquitetura e urbanismo, 47-62. http://dx.doi.org/10.18830/issn.1679-0944.n4.2007.12103.

Serviço Brasileiro de Apoio às Micro e Pequenas Empresas - SEBRAE. (2017). Referências Internacionais: Cidades inteligentes. Recuperado em 05 de janeiro de 2018, de http://ois.sebrae.com.br/publicacoes/smart-cities/.

Conferência das Nações Unidas sobre Comércio e Desenvolvimento - UNCTAD. (2010). Creative Economy: A Feasible Development Option. Recuperado em 16 de janeiro de 2018, de http://unctad.org/es/Docs/ditctab20103_en.pdf.

Zipori, E., \& Cohen, M.J. (2015). Anticipating post-automobility: design policies for fostering urban mobility transitions. International_Journal of Urban Sustainable Development, 147165. http://dx.doi.org/10.1080/19463138.2014.991737. 